\title{
Correction to: Bacterial reduction effect of four different dental lasers on titanium surfaces in vitro
}

\author{
W. Patrick Misischia ${ }^{1,2} \cdot$ Pinelopi Xenoudi ${ }^{1,3} \cdot$ Raymond A. Yukna $^{1,4} \oplus \cdot$ Michael J. Schurr $^{5}$
}

Published online: 24 August 2021

๑) Springer-Verlag London Ltd., part of Springer Nature 2021

\section{Correction to: Lasers Med Sci \\ https://doi.org/10.1007/s10103-021-03349-3}

After publication of this paper, it was found out that two paragraphs were omitted. The Acknowledgements and the Conflict of Interest sections.

The original article has been corrected.

Publisher's note Springer Nature remains neutral with regard to jurisdictional claims in published maps and institutional affiliations.

The original article can be found online at https://doi.org/10.1007/ s10103-021-03349-3.

Raymond A. Yukna

ray.yukna@cuanschutz.edu

1 Advanced Periodontal Therapies, Department of Surgical Dentistry, University of Colorado School of Dental Medicine, Aurora, CO, USA

2 Boulder, CO, USA

3 Division of Periodontology, Department of Orofacial Sciences, University of California, San Francisco, School of Dentistry, San Francisco, CA, USA

4 Department of Surgical Dentistry, University of Colorado School of Dental Medicine, 13065 E. 17th Avenue, Aurora, CO 80045, USA

5 Department of Immunology and Microbiology, University of Colorado School of Medicine, Aurora, CO, USA 